\title{
The Characteristics and Enlightenment of Training Model of Higher Music Schools in Italy
}

\author{
Xiaoxuan Wang 1,a, ${ }^{*}$, Li Jing ${ }^{2, b}$, Zheng Xiao ${ }^{3, c}$ \\ ${ }^{1}$ Assistant Professor, College Students Art Center, Hohai University \\ Nanjing, Jiangsu, China \\ ${ }^{2}$ Lecturer, Department of Music, Sichuan Preschool Teachers College Mianyang, \\ Sichuan, China \\ ${ }^{3}$ Dr. Business academy, Hohai University, Nanjing, Jiangsu, China \\ a279101993@qq.com, b491561523@qq.com, ‘453603843@qq.com \\ ${ }^{*}$ Corresponding Author
}

Keywords: music education model; music discipline construction; policy support

\begin{abstract}
This article tries to compare the music history of Chinese and Italian, the model of higher education institutions, the government support model and social attention. We collects some valuable official data and relevant research materials for reference between China and Italy.Comparing the National Statistical Yearbook between China and Italy. reflects on the status of music education in China and finds out the enlightenment of Italian music education to China.
\end{abstract}

\section{意大利高等音乐学府培养模式特点及启示}

\author{
王晓璇 $1, a,{ }^{*}$ ，李婧 $2, b$ ，郑晓 3,c \\ 1.河海大学 大学生艺术中心 助教 南京, 江苏, 中国 \\ 2.四川幼儿师范高等专科学校 音乐系 讲师 绵阳, 四川, 中国 \\ 3.河海大学 商学院 博士 南京, 江苏, 中国 \\ a279101993@qq.com, b491561523@qq.com, ‘453603843@qq.com \\ *通讯作者
}

关键词: 音乐教育模式; 音乐学科建设; 政策支持

中文摘要.本文试从中意音乐文化历史、高等学府培养模式、政府扶持模式及社会关注度等方 面进行对比, 搜集了中意两国有借鉴价值的官方数据及相关的研究资料, 对比了近年来意大 利与中国国家统计年鉴中音乐相关内容，反思我国音乐教育的现状，找出意大利音乐教育对 我国的启示。

\section{1. 引言}

作为文艺复兴发源地，意大利素以“艺术之国”著称。其音乐文化源远流长，俨然已成为 全人类共同的宝贵文化遗产。现代意大利高等音乐院校教育，不仅保留了其极具历史积淀的 丰富教育经验, 也拥有颇具特色的高等音乐学府教育模式。其作为我国一带一路战略沿线上 重要的合作国家, 从古至今都时刻保持紧密的文化与艺术交流。身为高校老师, 我们应该发 
挥出新时代“马可波罗”的身份角色, 将艺术之国——意大利的高等音乐学府成熟且有效的培 养模式进行借鉴与吸收。

\section{2. 意大利高等音乐学府起源及发展}

意大利音乐具有悠远的历史。早在 16 世纪，便涌现出许多音乐大师，如著名作曲家斯 卡拉第、蒙特威尔第等。16 世纪中期, 意大利出现了世界上第一批音乐学院---那不勒斯音乐 学院和威尼斯音乐学院。这些维形对欧洲音乐教育产生了深远影响。据统计, 在这片 30 万平 方公里的土地上, 拥有着多达 79 所音乐学院, 其中公立音乐学院 57 所, 私立音乐学院 22 所。 深厚历史酝酿下的意大利现代高等音乐学府, 符合成为我国音乐教育借鉴对象的条件。如今, 意大利高等学府发展良好, 拥有大量专业性强、经验丰富的师资团队, 为社会培养了众多专 业扎实、天赋优越的毕业生, 形成了其注重实效、灵活自主的系统教学模式, 建立了多元化、 多层次的音乐教育体系。

\section{3. 意大利与我国音乐教育模式对比}

习近平总书记在十九大报告中提出：“社会主义建设进入了新时代，我国社会主要矛盾 已经转化为人民日益增长的美好生活需要与不平衡不充分的发展之间的矛盾。”在这一特殊 的历史时期, 我国的高等音乐教育也同样面临这类问题: 东西部群众音乐基础差异悬殊, 教 学模式不够细化, 培养模式亟需完善。新形势下, 高等音乐教育如何转变发展模式是我们思 考的。意大利多年成熟的高等音乐教育模式有许多值得借鉴之处。

\section{1 国民对音乐艺术参与程度对比}

近年来, 中国的经济发展举世瞩目, 相对来说, 音乐教育的发展却滞后不少。从下表不 难看出, 我国民众对音乐艺术的参与度还很薄弱, 远低于意大利的平均水平。音乐基础的不 稳固也间接导致了国内音乐顶尖人才的贵乏。要解决这样的现状, 政府应加大支持力度, 营 造出更加适合音乐艺术人才发展的良好社会环境、提供更加优惠的国家政策、建立多层次的 就业环境，将音乐基础建设作为长期任务来对待。

图表一: 中意两国每年欣赏音乐会频率对比

\begin{tabular}{|l|r|r|r|r|}
\hline 中 国 & 2013 & 2014 & 2015 & 2016 \\
\hline 人口数 (万人) & 136072 & 136782 & 137462 & 138271 \\
\hline 每年欣赏音乐会演出人次 (万人) & 392 & 497 & 548 & 628 \\
\hline 年欣赏音乐会次数 (每百人) & 0.29 & 0.36 & 0.40 & 0.45 \\
\hline 意大利 & 2013 & 2014 & 2015 & 2016 \\
\hline 人口基数 (万人) & 5978 & 6014 & 6111 & 6201 \\
\hline 每年欣赏音乐会演出人次 (万人) & 1608 & 1654 & 1986 & 2056 \\
\hline 古典音乐会欣赏人次 (万人) & 544 & 559 & 581 & 597 \\
\hline 其他音乐会欣赏人次 (万人) & 1064 & 1095 & 1406 & 1560 \\
\hline 年欣赏音乐会次数 (每百人) & 26.90 & 27.50 & 32.50 & 33.16 \\
\hline
\end{tabular}

\section{2 音乐基础发展程度对比}

通过查阅我国统计年鉴我们发现, 我国的东、中、西部地区, 由于经济发展水平及地域 文化的因素, 每年欣赏音乐会人次呈现“东高西低”的分布格局, 部分西部地区民众参与度极 低。很显然, 这样的不平衡制约了我国音乐教育的整体发展水平。相比而言, 意大利南方经 济发展程度虽远低于北方, 但南北方民众参与音乐会的人次并无明显差异。只有妥善解决好 教育发展不平衡问题，才可以有效的提升我国高等音乐教育整体水平。在我国东部发达地区， 多个城市音乐会场馆等硬件设施方面已优于意大利, 但民众参与音乐会的比例仍不高。究其 
原因, 很大程度上与音乐表演的举办方式和收费模式有关。意大利举办音乐会多在教堂举行, 民众可免费便捷的参与。这种模式使一些中小音乐团体获得了成长的机会, 也满足了民众的 音乐需求。结合我国国情, 政府应创新音乐表演模式, 为民众提供各类演出场所, 使音乐表 演成本更低、参与度更高。

\section{3 音乐院校的发展仍处于初级阶段}

通过比较分析中意两国的招生情况, 预计我国未来很长一段时间招生比例都难以达到较 高的水平。特别是近几年, 我国音乐毕业生招生总规模虽保持增长, 但毕业生就业率却出现 了小幅下滑。就业难、就业面窄、理论知识薄弱、艺术实践能力差等多种问题屡见不鲜。作 者通过走访江苏省多所设置音乐专业的高等院校可以发现, 高等音乐专业教师的招聘需求近 年来呈现了较大幅度的萎缩, 目前虽有许多工科院校开始陆续加强了音乐类学科建设, 但综 合来看其发展形势仍不容乐观。结合两国高等音乐学府教学体制分析, 中国音乐教育的课程 结构相对固化, 毕业生的择业范围较窄。而意大利教学体制结构的多元化促使人才趋于多元 化, 学生个人能力的多元化也造就了就业面的多元化, 音乐毕业生不光可以在学校、音乐团 体工作, 还可以在很多我们认为的非主流岗位任职, 如电影配乐师、音乐制作人、音像制作 人、音乐顾问等等。如何进行更为灵活的学科建设工作, 增强毕业生的就业竞争力, 加强教 师人才队伍储备建设等都是我们急需解决的问题。

图表二: 中意两国音乐学院招生情况

\begin{tabular}{|l|r|r|r|}
\hline \multicolumn{1}{|c|}{ 中 国 } & 2014 & 2015 & 2016 \\
\hline 音乐学院招生人数 & 10160 & 10388 & 10491 \\
\hline 全国本科招生人数 & 3814331 & 3834152 & 3894184 \\
\hline 比例 & $0.266 \%$ & $0.271 \%$ & $0.269 \%$ \\
\hline 音乐学院毕业生人数 & 9942 & 10235 & 10338 \\
\hline 全国本科毕业生人数 & 3199716 & 3413787 & 3585940 \\
\hline 比例 & $0.311 \%$ & $0.300 \%$ & $0.288 \%$ \\
\hline 音乐学院硕士招生人数 & 1189 & 1275 & 1343 \\
\hline 全国硕士招生人数 & 540919 & 548689 & 570639 \\
\hline 比例 & $0.220 \%$ & $0.232 \%$ & $0.235 \%$ \\
\hline 音乐学院硕士毕业人数 & 1061 & 1065 & 1129 \\
\hline 全国硕士毕业生人数 & 460487 & 482210 & 497744 \\
\hline 比例 & $0.230 \%$ & $0.221 \%$ & $0.227 \%$ \\
\hline
\end{tabular}

\begin{tabular}{|l|r|r|r|}
\hline \multicolumn{1}{|c|}{ 意大利 } & 2013 & 2014 & 2015 \\
\hline 音乐学院招生人数 & 3601 & 3422 & 3601 \\
\hline 全国本科招生人数 & 185452 & 212782 & 212458 \\
\hline 比例 & $1.942 \%$ & $1.608 \%$ & $1.695 \%$ \\
\hline 本科毕业生人数 & 3423 & 2977 & 3413 \\
\hline 全国本科毕业生人数 & 185452 & 212782 & 212458 \\
\hline 比例 & $1.846 \%$ & $1.399 \%$ & $1.606 \%$ \\
\hline 音乐学院硕士招生人数 & 2724 & 2686 & 2949 \\
\hline 全国硕士招生人数 & 185643 & 180038 & 186547 \\
\hline 比例 & $1.467 \%$ & $1.492 \%$ & $1.581 \%$ \\
\hline 硕士毕业人数 & 1919 & 1538 & 1705 \\
\hline 全国硕士毕业生人数 & 113420 & 115385 & 117999 \\
\hline 比例 & $1.692 \%$ & $1.333 \%$ & $1.445 \%$ \\
\hline
\end{tabular}




\section{4 音乐教育的结构性及毕业生就业问题}

经过改革开放以来 30 多年的不解努力, 我国的经济增长有目共睹, 高速的经济发展支撑 了音乐文化的蓬勃发展。时至今日, 音乐文化产业的市场规模已相当巨大，一大批当红明星、 经纪公司、音乐出版商不断涌现。相当的产值和利润都流向了这些顶尖的公司和个人。但是 流行音乐“热”, 古典音乐“冷”的情况仍普遍存在, 流行音乐侵占了许多其他类型音乐从业人 员本应拥有的社会资源。如何维护音乐市场公平、健康、稳定的发展, 是我们接下来面临的 问题。只有解决好这些问题, 我国高等音乐人才的贵乏可得到根本解决。只有从国家层面出 发, 在提升教育质量的同时, 更加注重择业通道的建立。解决崇尚流行音乐忽视传统音乐的 现状, 提升社会关注度、加强政府财政支持、拓宽学生择业面, 使我国音乐教育走上健康、 良性、可持续发展的轨道。

\section{4. 意大利高等教育模式对我国的启示}

音乐是一个时代的文明象征, 是不可或缺的文化符号。习近平总书记在十九大报告中强 调: “文化是国家、民族的灵魂。我们要坚持中国特色社会主义文化发展道路, 建设社会主义 文化强国; 要繁荣发展社会主义文艺。发扬艺术民主, 推动文艺创新。倡导讲品位、讲格调、 讲责任, 抵制低俗、庸俗、媚俗。社会的主要矛盾已转化为人民日益增长的美好生活需要和 不平衡不充分的发展之间的矛盾, 永远把人民对美好生活的向往作为奋斗目标! ”十九大精神 为我国今后的音乐艺术教育道路指明了发展方向, 高等音乐教育发展与实现美好生活的奋斗 目标息息相关。

\section{1 因材施教、丰富灵活的教学课程设置}

意大利专业课程所具备开放性和宽容度是值得我们借鉴的。其倡导灵活的自主学风, 固 定教材的授课比例低, 考核也更多尝试表演及面试。在每学期开学前后, 让学生自由寻找合 适自己的专业老师进行沟通, 学校定期搜集学生的意见和想法, 除了统一的理论课程之外, 其它与本专业有关的专业实践课程都可以和老师协商开展。意大利国立音乐学院的专业、课 程设置、教师队伍专业水平在全国范围内大体上是平均的, 这更有利于音乐教育的整体发展。

\section{2 优秀师资队伍选拔及资源 “共享”}

从古至今, 意大利那些在音乐领域拥有高超技艺的音乐家, 不仅获得了良好的社会声誉 且受到广大人民群众的爱戴和尊重, 是人们羡慕和崇拜的对象, 而且也都担负了培养音乐人 才的任务, 成为了高校的专业教授, 如此的传统习惯也沿袭至今。我国若想造就出这样一批 高水准的师资队伍, 就应当提高音乐教师的社会地位及福利, 令公众更加重视音乐教育事业, 使社会高端人才不断涌入音乐行业, 形成音乐艺术发展的良性循环。

\section{3 低廉的学费和对学生的优惠政策。}

意大利大学一直保持传统, 拒绝将教育作为盈利产业, 公立音乐学院学费对学生免费, 只在入学时需要交少量注册费。这与国内音乐学院动轧上万元的学费形成鲜明对比。音乐学 生带上学生证前往剧院听音乐, 会享受折扣, 有时甚至可以免费观看。学生外出游玩时, 则 会享受欧洲多国多个景点的免费游览或是半价, 这有更利于塑造一批品学兼优的学生并激发 他们努力提高自身素质的动力。

\section{4 丰富的艺术实践与学习观摩机会}

在意大利每个大区、每个城市甚至每个乡村都会拥有大量的非专业乐团。其中包括音乐 学院的学生、理工科院校的学生、综合性大学的大学老师、医生、家庭妇女、退休老人、政 府职员、企业科研人员等等, 且其音乐演奏水平和音乐素养都很高。在音乐学院, 每年校长 
和专业老师都会制定出来年的演出计划。将高雅文化艺术推广到社会, 提高了民众的艺术修 养，起到了“润物无声、育人无形”的作用.

\section{5. 结论}

作为一门高雅艺术，音乐离不开良好的经济基础支持。根据整理的资料分析,意大利政府 财政多年以来保持了对艺术教育方面较高的倾斜力度。充足的资金使意大利高等学府拥有更 多资源来培养学生的音乐素养, 多年的积淀不仅使学校的音乐教育底蕴深厚, 也促使意大利 高等音乐学府在音乐教育模式不断推陈出新。其音乐高等教育模式成功的若干关键因素, 值 得我国研究。十九大报告中描述的美好生活最重要的是为国民带来精神上的满足。音乐教育 正是唤起人们心中的强烈共鸣, 使人获得精神愉悦的一种有效途径。是人类精神文明的结晶, 也是社会文明程度的标志。它还表现出一种广泛的渗透功能. 在当今社会高工作压力的条件 下为人们保持身心健康、维护社会稳定繁荣不无裨益。在即将进入全面建成小康社会的决胜 之际, 在社会需求转变的关键时刻, 国家对音乐人才的需求显得尤为迫切。高等院校音乐教 育发展应紧密地与国家政策相结合, 积极争取政府各项支持, 营造良好的政策环境。从社会、 学校双方面入手, 积极拓展音乐专业学生的就业面, 使音乐教育能够紧跟时代的步伐, 不断 发扬光大。

\section{References}

[1] China National Statistical Bureau,China Statistical Yearbook. China Statistics Press, 2013-2016

[2] Italian National Statistical Bureau. Italian Statistical Yearbook. Italian National Bureau of Statistics, 2013-2016

[3] Liu Xin Yin Aiqing Status Quo of Music Teachers Training in Italian Ordinary Schools and Its Enlightenment to China. Chinese Music, vol.4,pp.240-243,2007

[4] Ran Yu The Characteristics and Reflection of Saitama Italian Higher Art Education. Art Education, vol.10,pp.34-35,2009

[5] Liu Bing Vocal Music Teaching at Naples College of Music in Italy, Singing Arts, vol.2,pp.57-61,2013

[6] Differences between Italian Higher Education and Chinese Higher Education. Educational Modernization, vol.19,pp.83-89,2017

[7] Sun Leilei Enlightenment from the Reform of the Italian Conservatory of Music on Music Education in Normal Colleges in China. Journal of Northeast Normal University (Philosophy), vol.4,pp.127-132,2012

[8] Xian Tao Italian and German music education personnel training model and its inspiration to China. Journal of Shenyang Conservatory of Music, vol.4,pp.273-274,2015

[9] Li Mingyue discusses Italian music education and vocal music teaching. Journal of Shenyang Conservatory of Music, vol.11,pp.42-43,2014

[10] European Conservatory of Music and Shanghai Conservatory of Music. Music Art, vol.3,pp.65-73,2007 